\title{
RETRACTED ARTICLE: Robust and efficient image watermarking technology in big multimedia data environmental
}

\author{
Hu Zhen-tao ${ }^{1} \cdot$ Zepeng Wang $^{2}$ (D)
}

Received: 3 November 2017 /Revised: 13 November 2017 / Accepted: 20 November 2017 /

Published online: 29 November 2017

(C) Springer Science+Business Media, LLC, part of Springer Nature 2017

The Editor-in-Chief has retracted this article [1] which was published as part of special issue "Multi-source Weak Data Management using Big Data" because its content has been duplicated from an unpublished manuscript authored by Ritu Agrawal and Manisha Sharma without permission. In addition, there is evidence suggesting an attempt to subvert the peer review process.

Author Zepeng Wang stated on behalf of both authors that they agree to this retraction.

\section{References}

1. Zhen-tao, H. \& Wang, Z. Robust and efficient image watermarking technology in big multimedia data environmental. Multimed Tools Appl (2017). https://doi.org/10.1007 /s11042-017-5442-y

Electronic supplementary material The online version of this article (https://doi.org/10.1007/s11042-0175442-y) contains supplementary material, which is available to authorized users.

\section{Zepeng Wang}

1422617933@qq.com

1 College of Computer and Information Engineering, Henan University, Kaifeng, China

2 School of CSIE, Hefei University of Technology, Hefei, China 